\title{
Study of metronomic chemotherapy in cancer patients at a tertiary care centre in South India
}

\author{
Mohammed Ashraf K. ${ }^{1, *}$, Nishitha Shetty ${ }^{2}$, R. Arunachalam ${ }^{3}$, Paraashar R. Rai ${ }^{4}$, Arpitha ${ }^{5}$ \\ ${ }^{\mathbf{1}}$ Resident, ${ }^{\mathbf{2}}$ Assistant Professor, ${ }^{\mathbf{3}}$ Professor, ${ }^{4}$ Resident, ${ }^{5}$ Junior Clerk, ${ }^{\mathbf{1}, \mathbf{3}}$ Dept. of Medicine, ${ }^{\mathbf{2}, \mathbf{4}, \mathbf{5}}$ Dept. of medical Oncology, Father \\ Muller Medical College, Mangaluru, Karnataka, India
}

*Corresponding Author:

Email: ashrafkargil5@gmail.com

\begin{abstract}
The past century has witnessed a vast progress in the field of cancer chemotherapy. Angiogenesis is the foundation of cancer existence. Metronomic chemotherapy by definition is the administration of low dose chemotherapy at regular intervals with no long-standing drug free intervals with the aim to achieve continual blood levels of the chemotherapeutic drug, without the severe toxicity profile or the long-standing drug free breaks as seen in maximum tolerated dose (MTD). We conducted a study with the aim to see the role of metronomic chemotherapy in head and cancers at a teritiary care of south India.

Materials and Method: We did a retrospective analysis of patients diagnosed with cancer of the head and neck who received metronomic chemotherapy in a tertiary cancer care centre for one year. A total of 46 patients were included in the study. Patients who were at least 18 years old and who had received metronomic chemotherapy for cancer were included in the study. The subjective response was assessed based upon the patients symptoms and clinical examination, and objective response was assessed using radiological modality wherever available. The study was conducted after having been approved by the institution review board.

Data and Statistical Analysis: The Chi Square test was performed to identify the statistical significance between metronomic chemotherapy and the variables analyzed and confidence interval was calculated.

Results and Observations: In our study we had 46 patients who were diagnosed with head and neck cancer on metronomic chemotherapy and met the criteria and gave informed consent for participation in the study. The mean age of patients was 57.16 years with 33 males and 13females. Majority (54\%) were in stage 4 .In this study $74 \%$ were symptomatically better, $18 \%$ got worse, $4 \%$ were stable and $4 \%$ had no change in their symptomatic profile.

Interpretation and Conclusion: In palliative cancer care patients Metronomic chemotherapy is a good option in countries where patients are financially poor where health care facilities are not easily accessible. It does not require close monitoring unlike conventional chemotherapy, as the side effect profile is low.
\end{abstract}

Keywords: Angiogenesis, Chemotherapy, Metronomic chemotherapy, Tumor.

\section{Introduction}

The past century has witnessed a vast progress in the field cancer chemotherapy. ${ }^{1}$ Angiogenesis is the foundation of cancer existence. Tumour endothelial cells have revealed multiplicity at a lesser rate as compared to cancer cells. Cancer models have shown that maximum tolerated dose chemotherapy drug regimens with prolonged drug free intervals feebly affect the endothelial cells. Maximum tolerated dose (MTD) chemotherapy is widely practiced and has been successful in achieving cure in Haematological malignancies but with varying results in advanced solid cancers. $^{2}$

Metronomic chemotherapy by definition is the administration of low dose chemotherapy at regular intervals with no long-standing drug free intervals with the aim to achieve continual blood levels of the chemotherapeutic drug, without the severe toxicity profile or the long-standing drug free breaks as seen in maximum tolerated dose (MTD). We conducted a study with the aim to see the role of metronomic chemotherapy in head and cancers at a teritiary care of south India.

\section{Materials and Method}

We did a retrospective analysis of 46 patients diagnosed with cancer who received metronomic chemotherapy in a tertiary cancer care centre for one year. Patients who were at least 18 years old and who had received metronomic chemotherapy for cancer were included in the study.

The following data was collected age, sex, diagnosis with staging, sequence of prior treatment received, duration of metronomic chemotherapy, reason for stoppage of metronomic chemotherapy, Response, Toxicity profile, and outcome. Degree of toxicity was assessed using the Common Terminology criteria for Adverse Events (CTCAE), version 4.0 The subjective response was assessed based upon the patients symptoms and clinical examination, and objective response was assessed using radiological modality wherever available. The study was conducted after having been approved by the institution review board.

\section{Data and Statistical Analysis}

The Chi Square test was performed to identify the statistical significance between metronomic chemotherapy and the variables analyzed and confidence interval was calculated. 


\section{Results and Observations}

In our study we had 46 patients who were diagnosed with head and neck cancer on metronomic chemotherapy and met the criteria and gave informed consent for participation in the study. The mean age of patients was 57.16 years with 33 males and 13 females. The indication was palliative in majority of patients. Out of the patients included in the study, $74 \%$ were symptomatically better, $18 \%$ got worse, $4 \%$ were stable and $4 \%$ had no change in their symptomatic profile. At the time of analysis, $58 \%$ were alive and $42 \%$ of patients had expired. $7 \%$ patients were being treated with curative intent, but majority $93 \%$ with palliative intent as represented in table 1 . The side effect profile was also well tolerated as depicted in table 2 .

Table 1: Demographic distribution of cases

\begin{tabular}{|c|c|c|c|c|}
\hline Name & Number & Age & Males & Females \\
\hline Head and Neck & 46 & 57.162 & 33 & 13 \\
\hline
\end{tabular}

Table 2: Stage of disease

\begin{tabular}{|c|c|c|c|c|c|c|}
\hline Name & Stage 1 & Stage 2 & Stage 3 & Stage 4 & $\begin{array}{l}\text { Stage Not } \\
\text { Available }\end{array}$ & Total \\
\hline Head and Neck & 0 & 2 & 9 & 25 & 10 & 46 \\
\hline
\end{tabular}

Table 3: Indication of chemotherapy

\begin{tabular}{|c|c|c|c|c|}
\hline $\begin{array}{c}\text { Indication For } \\
\text { Metronomic }\end{array}$ & Palliative & Neo adjuvant & Curative & Total \\
\hline Head and Neck & 35 & 8 & 3 & 46 \\
\hline
\end{tabular}

Table 4: Treatment regimen and patient response

\begin{tabular}{|c|c|c|c|c|c|}
\hline $\begin{array}{l}\text { Site of } \\
\text { cancer }\end{array}$ & Regimen & Toxicity & Response & $\begin{array}{c}\text { Symptomatic } \\
\text { benefit }\end{array}$ & $\begin{array}{c}\text { Reason for } \\
\text { stoppage }\end{array}$ \\
\hline $\begin{array}{l}\text { Head and } \\
\text { Neck } \\
\text { Carcinoma } \\
(43)\end{array}$ & $\begin{array}{l}\text { 1) Inj } \\
\text { Methotrexate } \\
\text { weekly :34 } \\
\text { 2)Tab } \\
\text { Methotrexate + } \\
\text { Tab Celecoxib: } \\
\text { 3)Tab Gefitinib } \\
\text { OD:9 } \\
\text { 4)Tab } \\
\text { Methotrexate + } \\
\text { Tab Endoxan:1 } \\
\text { 5)Tab Mtx + } \\
\text { Tab gefitinib:1 }\end{array}$ & $\begin{array}{l}\text { 1) } \\
\text { > Mucositis: } 6 \\
>\text { Leucopenia: } 3 \\
\text { Vomiting, : } 1 \\
\text { D Diarrhoea: } 1 \\
\text { > Fatigue: } 1 \\
>\text { Mucositis: } 2 \\
>\text { Nausea: } 1 \\
>\text { leucopenia: } 1 \\
>\text { Constipation: } 1 \\
\text { 1) Skin rash: } 2 \\
\text { 2) Nil } \\
\text { 3) Diarrhoea: } 1\end{array}$ & $\begin{array}{l}\text { Partial response: } \\
18 \\
\text { Complete } \\
\text { Response: } 0 \\
\text { No Response: } 1 \\
\text { Stable Disease: } 10 \\
\text { Not Applicable**: } \\
7\end{array}$ & $\begin{array}{l}\text { Worse: } 8 \\
\text { No change: } 2 \\
\text { Stable: } 2\end{array}$ & $\begin{array}{l}\text { Defaulted: } 17 \\
\text { No response: } 2 \\
\text { Expired : } 3 \\
\text { Not applicable*: } 6\end{array}$ \\
\hline
\end{tabular}

\section{Discussion}

Despite considerable progress in cancer research, current treatment protocols are unable to cure certain malignancies. Moreover, conventional chemotherapy and even new drug delivery systems lead to adverse drug reactions that restrict dosing and interferes the efficacy of anti-neoplastic drugs. So exploring new therapeutic targets as well as new therapeutic strategies are essential to improve cancer treatment.

The recent preclinical studies have suggested that frequent administration of low doses of certain antineoplastic drugs known as 'metronomic' chemotherapy, shows/enhances the anti-angiogenic property of the drugs. ${ }^{1-3}$ The effects of these metronomic protocols of anti-neoplastic agents may be further improved by concurrent administration of another agent that inhibits the processes of growth and tumor formation. The rationale behind the use of metronomic chemotherapy for longer duration is to minimize adverse drug reactions and to target both endothelial cells and tumor cells which are at proliferating stage. This concept was borne out of pioneer studies conducted by Klement et. al. ${ }^{4}$ and Browder et. al., ${ }^{5}$ on the anti angiogenic 
scheduling of cancer chemotherapeutic agents on cancers.

Metronomic chemotherapy is a treatment option that has not been entirely explored. Although it has been in use for more than a decade, there are no clear guidelines on the institution of therapy and treatment protocols, due to lack of randomized controlled trials. Studies currently underway aim at determining regimens designed for the treatment of particular types of cancer, assessment of response and duration of use of metronomic chemotherapy. ${ }^{3-6}$

The effectiveness of the metronomic chemotherapy with single agent MTD (Cisplatin) chemotherapy in patients with Metastatic, inoperable or relapsed squamous cell head and neck cancers was compared in a phase 2 randomized control trial. Progression free survival was significantly longer in patients receiving metronomic chemotherapy as compared to MTD chemotherapy group. In the metronomic chemotherapy arm, the overall survival was also significantly higher when compared to the MTD chemotherapy arm. In metronomic chemotherapy group there were fewer grade $3 / 4$ adverse effects. ${ }^{6}$ In this study also the side effect profile was well tolerated as depicted in table 2 .

Although in some poorly responsive cancers studies have shown questionable efficacy, ${ }^{7}$ in majority it has been shown to be well tolerated, having mild side effects like grade 1 /grade 2 cytopenia, grade 1 /grade 2 nausea, vomiting and fatigue. Although data on tolerance to metronomic chemotherapy is still limited, even in patients with advanced cancer, it has been shown to have substantial clinical benefit with minimal side effects. ${ }^{8,9}$

As compared to MTD chemotherapy metronomic chemotherapy is cost effective. It was found that low dose metronomic chemotherapy in patients with metastatic breast cancer, significantly brought down the cost of treatment, especially in those receiving targeted therapy, in a study evaluating the costs of administrating metronomic chemotherapy as compared to conventional chemotherapy ${ }^{10}$. In our study majority of the patients were started on oral drugs and were below the poverty line. The lower cost, better compliance with treatment, especially with patients on palliative care were the positive aspects.

Metronomic chemotherapy has been found to be effective, tolerable and have a positive impact on $\mathrm{QOL}^{11}$.The progression free survival was found to be 6 months and the overall survival 15 months without any grade 3 or 4 toxicities, In a study involving 41 elderly individuals suffering from advanced non small cell lung carcinoma on metronomic chemotherapy, at a median follow up of 20.2 months. At baseline and 4 months a FACT-L test was used to asses the quality of life and it suggested a significant improvement in mental, social, physical and emotional health of the patient, indicating a quality of life improvement ${ }^{12}$.In this study we did not analyse the quality of life.
Some disadvantage of our study include the fact that it is a retrospective study in which there is a chance for selection bias .Also we did not use any advanced imaging modalities to analyse the response to metronomic chemotherapy resorting to subjective symptomatic benefit ,clinical examination, and Chest $\mathrm{X}$-ray and Ultrasound.

\section{Conclusion}

Metronomic chemotherapy is a reasonable alternative to MTD in head and neck cancer, especially in palliative patients. It has shown reasonable response with symptomatic benefit, less toxicity and less cost of treatment and care of administration.

\section{References}

1. Vincent T. DeVita Jr. and Edward Chu. A History of Cancer Chemotherapy Cancer Res 2008;68:(21).

2. GatenbyRA.A change of strategy in the war on cancer. Nature 2009;28(7246):508-9.doi:10. 1038/459508a

3. HanahanD, BergersG,BergslandE.Less is more, regularly: metronomic dosing of cytotoxic drugs can target tumor angiogenesis in mice. J Clin Invest 2000;105(8):10457.doi:10.1172/JCI9872

4. Klement, G., Baruchel, S., Rak, J., Man, S., Clark, K., Hicklin, D.J., Bohlen, P. and Kerbel, R.S. (2000) Continuous Low-Dose Therapy with Vinblastine and VEGF Receptor-2 Antibody Induces Sustained Tumor Regression without Overt Toxicity. J Clin Invest 105, R15-R24.

5. Browder, T., Butterfield, C.E., Kräling, B.M., Shi, B., Marshall, B., O'Reilly, M.S. and Folkman, J. (2000) Antiangiogenic Scheduling of Chemotherapy Improves Efficacy against Experimental Drug-Resistant Cancer. Cancer Res 60,1878-1886.

6. Vijay Maruti Patil, Vanita Noronha, Shripad Dinanath Banavali et. al. A phase II study comparing metronomic chemotherapy with chemotherapy (single-agent cisplatin), in patients with metastatic, relapsed, or inoperable squamous cell carcinoma of head and neck. J Clin Oncol 2014;32:5s, (suppl; abstr 6017)

7. Kesari, S. et al. Phase II study of metronomic chemotherapy for recurrent malignant gliomas in adults. Neuro Oncol 2007;9:354-63.

8. Jurado Garcia, J. M. et al. Combined oral cyclophosphamide and bevacizumab in heavily pretreated ovarian cancer. Clin Transl Oncol 2008;10,583-6.

9. Glode, L. M., Barqawi, A., Crighton, F., Crawford, E. D. $\&$ Kerbel, R. Metronomic therapy with cyclophosphamide and dexamethasone for prostate carcinoma. Cancer 2003;98,1643-48.

10. G. Bocci1, M. Tuccori, U. Emmenegger, V. Liguori, A. Falcone, R. S. Kerbel \& M. Del Tacca. Cyclophosphamide-methotrexate 'metronomic' chemotherapy for the palliative treatment of metastatic breast cancer. A comparative pharmacoeconomic evaluation. Ann Oncol 2005;16:1243-52.

11. Iuliis FD, Vendittozzi S, Taglieri L, Salerno G, Lanza R, et al. (2016) MetronomicChemotherapy Preserves Quality of Life Ensuring Efficacy in Elderly Advanced Non SmallCell Lung Cancer Patients. Int J Cancer Clin Res 3:046 
12. Alagizy HA, Shehata MA, Hashem TA, Abdelaziz KK, Swiha MM. Metronomic capecitabine as extended adjuvant chemotherapy in women with triple negative breast cancer. 2015;8(1):22-7. doi:

10.1016/j.hemonc.2014.11.003. Epub 2014 Nov 26. 